\title{
APPLICABILITY OF MICRO-FIBRE REINFORCED CEMENTITIOUS COMPOSITES FOR THIN OVERLAYS IN CONSTRUCTION: EFFECT OF FIBRE TYPE AND DOSAGE
}

\author{
Arturs Lukasenoks ${ }^{1}$, Rolands Cepuritis ${ }^{2}$ \\ ${ }^{1}$ Riga Technical University, Latvia; ${ }^{2}$ Norwegian University of Science and Technology, Norway \\ arturs.lukasenoks@rtu.lv, rolands.cepuritis@ntnu.no
}

\begin{abstract}
Nylon and polyvinyl alcohol (PVA) micro-fibres with different geometries were used in 1 vol. \% dosage and polypropylene (PP) micro-fibres were used in 1, 1.5 and 2 vol. \% dosage to investigate rheological and mechanical properties of cementitious composites to be used for thin overlays. Slump-flow and visual stability index methods were used to characterise the rheological properties. Single crack tension and bending studies were carried out to evaluate the tensile and bending strength, as well as the post-cracking behaviour. Coupon samples $(100 \times 50 \times 25 \mathrm{~mm})$ were manufactured with a small notch $(2 \mathrm{~mm}$ deep and $0.7 \mathrm{~mm}$ wide) for single crack tension tests and beam samples $(40 \times 40 \times 160 \mathrm{~mm})$ with a notch $(5 \mathrm{~mm}$ deep and $0.7 \mathrm{~mm}$ wide) for bending tests. The results show that fibre geometry (Length/diameter $(L / d)$ ratio and specific surface area) and fibre dosage have a pronounced influence on the fresh state rheological properties of the cementitious composites. Tested composites with 1 vol. \% dosage showed tensile strain softening and insignificant deflection hardening after cracking and a major residual strength loss. Composite with 1.5 vol. \% dosage shows only deflection hardening, but composite with 2 vol. \% dosage shows both tensile strain and deflection hardening. Composite with 2 vol. \% dosage reachesthe significant tensile strength of $1.77 \mathrm{MPa}$ and bending strength of 12.47 MPa. The tests also indicated that fibres with $L / d$ ratio $<120$ can be practically used in mixes for the production of cementitious composites. By using this kind of fibres, it is possible to overcome technological problems that are associated with real production-introduction and dispersion large amounts of fibres, ensuring the stability of the mixture and casting a thin layer of the cementitious composite. Mechanical and rheological properties of the developed cementitious composites show great potential to be used in construction as thin overlays.
\end{abstract}

Keywords: cementitious composite, thin overlays, strain hardening, rheology.

\section{Introduction}

Cementitious composite is a special type of fibre reinforced concrete (FRC) with tailored properties. Various applications are known for cementitious composites in buildings and infrastructure: floor levelling or repair, precast element topping layer and repair of the road, bridge and parking decks. Cementitious composite layer bonding to the subbase is the main distinctive feature of the sheet products. Therefore, thin layer durability is defined by its ability to adhere to the subbase, resistance to its deformations and external impact and traffic loads. Economic feasibility for practical cementitious composite application in large scale is crucial. There are several successful attempts to achieve cementitious composite strain hardening behaviour with powder type mixes - the maximum aggregate size of $0.3 \mathrm{~mm}$ (1). Some further developments show that aggregates with up to $1.0 \mathrm{~mm}$ can be used (2). Such small aggregate size more likely will result in elevated material shrinkage, which has to be compensated. Micro-fibre reinforcement for sheet products is reported to be in the range of 3-10\%, which requires special measures to introduce fibres and process the cementitious composite (3). However, careful material design can result in more moderate fibre dosages - below $2.5 \%$ vol. fraction (4). Unfortunately, large-scale application of the cementitious composite requires using widely available materials, both from the economic and practical standpoint. The lack of focus on these aspects in the current development of the cementitious composite materials is one of the reasons for the currently low level of practical applications.

This paper presents a study on an attempt to develop and investigate cementitious composite rheological, mechanical and technological properties to enable its application in practical production for thin overlays. Therefore, maximum aggregate size of $4 \mathrm{~mm}$ (typical maximum size of sand aggregates in concrete production) and fibres in the range of 1.0-2.0\% vol. fraction is used.

\section{Materials and methodology}

Mix design

Six different mixes were developed with a maximum aggregate size of $4 \mathrm{~mm}$ and flowable workability to investigate the fibre type and dosage influence on cementitious composite properties and application technological parameters. The used material compositions are presented in Table 1. 
Cemex CEM I $42.5 \mathrm{~N}$ cement was used as the binder. Naturallyfractioned sand of 0-4 mm gradation from Garkalnes Grants was used as the aggregate. PrimeFlow high range water reducing admixture (HRWRA) from Primekss Group was used to achieve the workability of the cementitious composites. Viscostar 6K viscosity modifying admixture (VMA) from Mapei and natural wollastonite fibre slurry were used as a stabilizer to control bleeding of the mixes. The water-to-cement $(w / c)$ ratios of the mixes were in the range of 0.235 to 0.300 . The used reinforcement included two different types of polypropylene fibres (PP), nylon fibres and polyvinyl alcohol (PVA) fibres. Fibres dosage in the cementitious composites was 1.0 (M1 - M4), 1.5 (M5) and 2.0 (M6) vol. \%, accordingly.

Table 1

Material compositions for cementitious composites

\begin{tabular}{|l|c|c|c|c|c|c|}
\hline \multicolumn{1}{|c|}{ Material } & $\begin{array}{c}\mathbf{M 1}, \\
\mathbf{k g} \cdot \mathbf{m}^{-3}\end{array}$ & $\begin{array}{c}\mathbf{M 2}, \\
\mathbf{k g} \cdot \mathbf{m}^{-3}\end{array}$ & $\begin{array}{c}\mathbf{M 3}, \\
\mathbf{k g} \cdot \mathbf{m}^{-3}\end{array}$ & $\begin{array}{c}\mathbf{M 4}, \\
\mathbf{k g} \cdot \mathbf{m}^{-3}\end{array}$ & $\begin{array}{c}\mathbf{M 5}, \\
\mathbf{k g} \cdot \mathbf{m}^{-3}\end{array}$ & $\begin{array}{c}\mathbf{M 6} \\
\mathbf{k g} \cdot \mathbf{m}^{-3}\end{array}$ \\
\hline CEM I 42.5 N cement & 1200 & 1200 & 1200 & 1000 & 1000 & 1200 \\
\hline Water & 300 & 336 & 300 & 235 & 300 & 360 \\
\hline 0-4 mm sand & 687 & 581 & 591 & 1070 & 933 & 566 \\
\hline PrimeFlow HRWRA & 33.6 & 33.6 & 33.6 & 28 & 15 & $\begin{array}{c}1.6 \\
(1.8 \%)\end{array}$ \\
\hline Viscostar 6K VMA & 4.5 & 4.5 & 4.5 & 2.1 & 2 & 5 \\
\hline Actigel Wollastonite fibre & - & - & - & - & 2 & 2.4 \\
\hline $\begin{array}{l}\text { Nylon fibres }(L-18 \mathrm{~mm}, d-0.026 \\
\text { mm) }\end{array}$ & 11.4 & - & - & - & - & - \\
\hline $\begin{array}{l}\text { PP fibres }(L-12 \mathrm{~mm}, d-0.022 \\
\text { mm) }\end{array}$ & - & 9 & - & - & - & - \\
\hline PVA fibres $(L-9 \mathrm{~mm}, d-0.04 \mathrm{~mm})$ & - & - & 11 & - & - & - \\
\hline PP fibres $(L-24 \mathrm{~mm}, d-0.2 \mathrm{~mm})$ & - & - & - & 9 & 13.5 & 18 \\
\hline w/c ratio & 0.250 & 0.280 & 0.250 & 0.235 & 0.300 & 0.300 \\
\hline
\end{tabular}

Samples

Samples for single crack tension tests were the first cast in a larger panel of $30 \times 150 \times 600 \mathrm{~mm}$ and afterwards cut in $30 \times 50 \times 150 \mathrm{~mm}$ tension samples (also called coupons). A notch of $2 \mathrm{~mm}$ depth and $0.7 \mathrm{~mm}$ width was made all around in the middle of a tension sample. Single crack tension setup is shown in Fig. 1 (on the right). Samples for single crack bending tests were cast in standard $40 \times 40 \times 160 \mathrm{~mm}$ moulds. A notch of $5 \mathrm{~mm}$ depth and $0.7 \mathrm{~mm}$ width was made in the bottom of the beam. Single crack bending setup is shown in Fig. 1 (on the left). Samples for compressive strength were cast in $100 \times 100 \times 100 \mathrm{~mm}$ moulds.

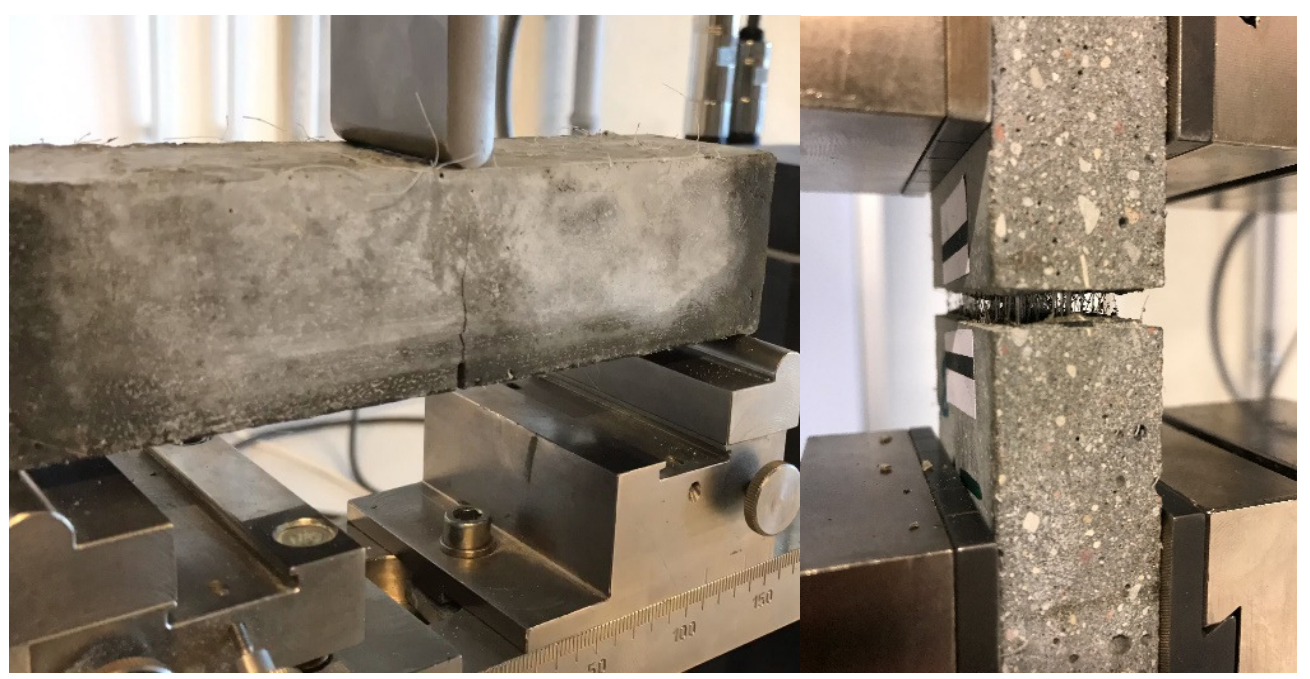

Fig. 1. Single crack bending (on the left) and tension (on the right) test setup 


\section{Testing}

Fresh cementitious composite rheological properties and workability were determined by measuring the concrete slump-flow value according to EN 12350-8, as well as determining the visual stability index (VSI), as described in (5).Ten samples were tested for each method, i.e. tension and bending. Narrow notch was made in the samples to ensure single crack formation in predefined section during tests as described in (6) and (7). Tests were performed in tension and bending with a load rate of $0.3 \mathrm{~mm} \cdot \mathrm{min}^{-1}$ and deformations measured with a non-contact extensometer.

\section{Results and Discussion}

Fresh and hardened cementitious composite properties are presented in Table 2. Slump flow spread edge (shown in Fig. 2 and Fig. 3) was visually examined to determine the visual stability index. Cementitious composite mixes M1 - M5 were stable (VSI 0-1), mix M6 showed slight bleeding (VSI 2).

Table 2

Fresh and hardened cementitious composite properties

\begin{tabular}{|l|c|c|c|c|c|c|}
\hline Cementitious composite mix & M1 & M2 & M3 & M4 & M5 & M6 \\
\hline Cement paste volume in the mix, $\mathbf{l}^{-\mathbf{3}} \mathbf{m}^{-3}$ & 713 & 749 & 713 & 599 & 662 & 788 \\
\hline Slump-flow, mm & 540 & 440 & 680 & 700 & 555 & 375 \\
\hline Visual stability index (VSI) & 1 & 1 & 1 & 0 & 1 & 2 \\
\hline Compressive strength, MPa & 70.4 & 55.1 & 69.0 & 93.0 & 67.4 & 65.8 \\
\hline
\end{tabular}

From Table 2 it can be seen that M4 has by far the lowest cement paste volume and simultaneously the highest slump-flow spread diameter between the mixes with $1 \%$ fibre vol. fraction. This fact showed that PP fibre with Lenght/diameter $(L / d)$ ratio 120 is the most appropriate fibre among the other tested fibres for cementitious composites with high dosages. Cementitious composites with the same fibre at 1.5 and $2.0 \%$ vol. fraction had increased paste volumeto ensure workable and stable mix.

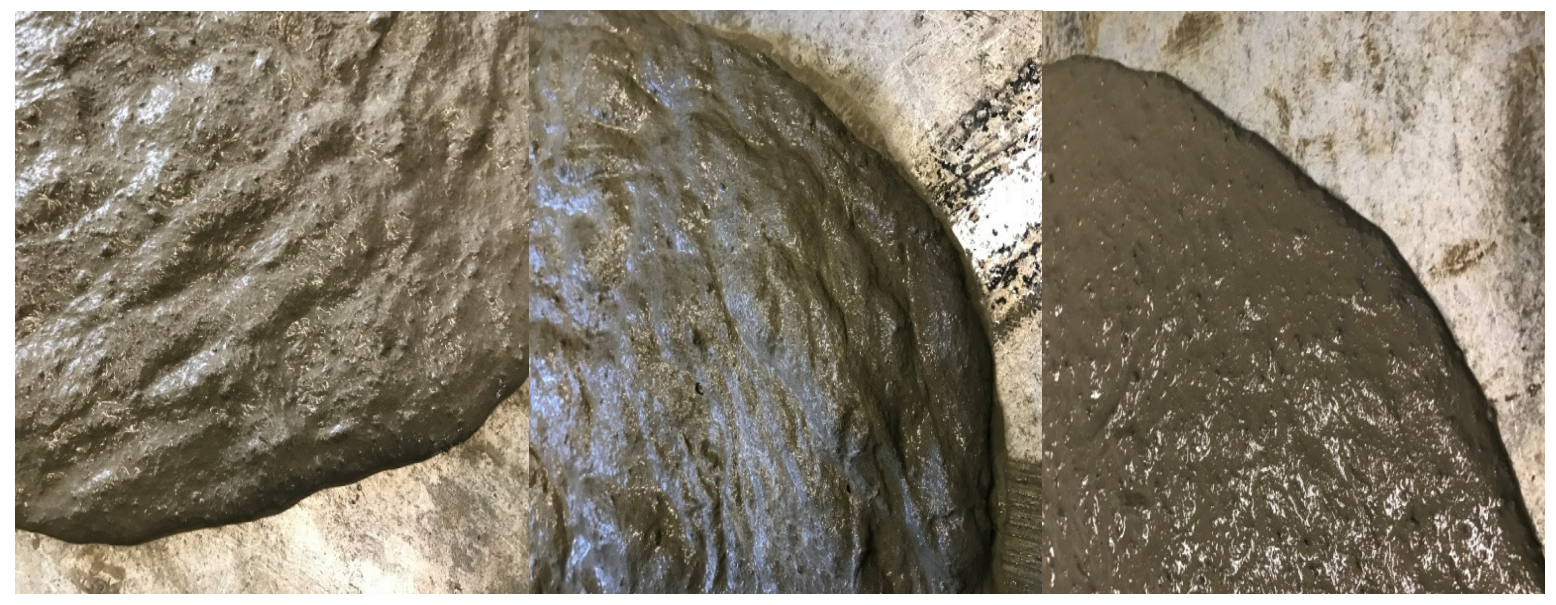

Fig. 2. Cementitious composite spread edge for visual mixture stability assessment, from left to right: $M 1, M 2$ and $M 3$

Geometrical properties of the used fibres are presented in Table 3. In addition, the total number of fibres and their surface area in a volume unit of the mix was estimated (see Table 3). The data in Table 3 show that the fibre dosage and surface area show clear influence on the slump-flow spread diameter: increased fibre surface area and fibre volume fraction reduce fresh cementitious composite rheological properties.

The determined single crack bendingbehaviour curves of the cementitious composites are shown in Fig. 4 and the tensile behaviour in Fig. 5. Results in the figures are shown up to $4 \mathrm{~mm}$ of crack mouth opening displacement (CMOD) on the left-hand side and initial crack opening up to $0.15 \mathrm{~mm}$ shown on the right-hand side. Summary of the values corresponding to the key-points of the curves is presented in Table 4 and Table 5. 


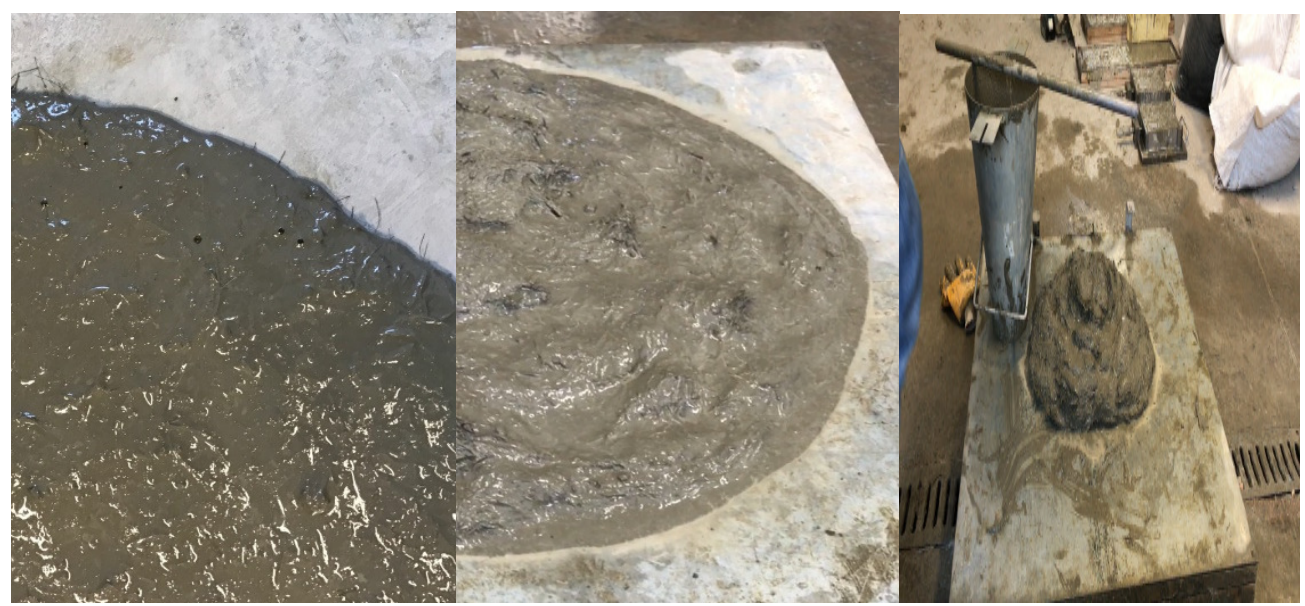

Fig. 3. Cementitious composite spread edge for visual mixture stability assessment, from left to right: M4, M5 and M6

Table 3

Nylon, PP and PVA fibre geometrical properties, number of fibres and their surface area per cubic meter of fresh cementitious composite

\begin{tabular}{|c|c|c|c|c|c|c|c|c|c|}
\hline \multirow[b]{2}{*}{$\begin{array}{l}\text { Cementitious } \\
\text { composite mix }\end{array}$} & \multirow[b]{2}{*}{$\begin{array}{c}\text { Fibre } \\
\text { material }\end{array}$} & \multirow[b]{2}{*}{$d, \mathbf{m m}$} & \multirow[b]{2}{*}{$\begin{array}{c}L, \\
\mathbf{m m}\end{array}$} & \multirow[b]{2}{*}{$L / d$} & \multicolumn{2}{|c|}{ Single fibre } & \multicolumn{2}{|c|}{ Per cubic meter } & \multirow[b]{2}{*}{$\begin{array}{c}\text { Slump- } \\
\text { flow, } \\
\text { mm }\end{array}$} \\
\hline & & & & & $\begin{array}{c}\text { Surface } \\
\text { area, } \\
\text { mm }^{2}\end{array}$ & $\begin{array}{c}\text { Volume, } \\
\text { mm }^{3}\end{array}$ & $\begin{array}{c}\text { Number } \\
\text { of fibres } \\
\times 10^{6}\end{array}$ & $\begin{array}{l}\text { Surface } \\
\text { area, } x \\
10^{6} \mathrm{~mm}^{2}\end{array}$ & \\
\hline M1, 1 & Irlo & & 18 & 692 & 1.47 & & 1046 & 1538 & 540 \\
\hline M2, & & & 12 & 545 & 0.83 & & 21 & & \\
\hline M3, & & & 9 & 225 & 1.13 & & 884 & & 680 \\
\hline$\%$ & $\mathrm{PP}$ & 0.2 & 24 & 120 & 15.08 & & 13 & 200 & 700 \\
\hline M5, 1.5 vol. \% & $\mathrm{PP}$ & 0.2 & 24 & 120 & 15.08 & 0.7540 & 20 & 300 & 555 \\
\hline M6, 2.0 vol. \% & PP & 0.2 & 24 & 120 & 15.08 & 0.7540 & 27 & 400 & 375 \\
\hline
\end{tabular}

The composites M1 and M3 have the highest peak bending strength and also considerable residual strength loss after the first crack. From the Fig. 4 and Table 4 it can be seen that M1 - M4 have postcracking minimum $30-60 \%$ lower than the peak strength. Though, there is almost no strength reduction after the first crack appearance for M5, but has steady strength increase up to $0.15 \mathrm{~mm}$ of CMODand much steeper increase until reaches maximum strength at approximately $1.3 \mathrm{~mm}$. Bending strength point and post-cracking minimum cannot be distinguished from the bending curve for M6. Strain hardening behaviour in bending can be observed for both cementitious composites M5 and M6.
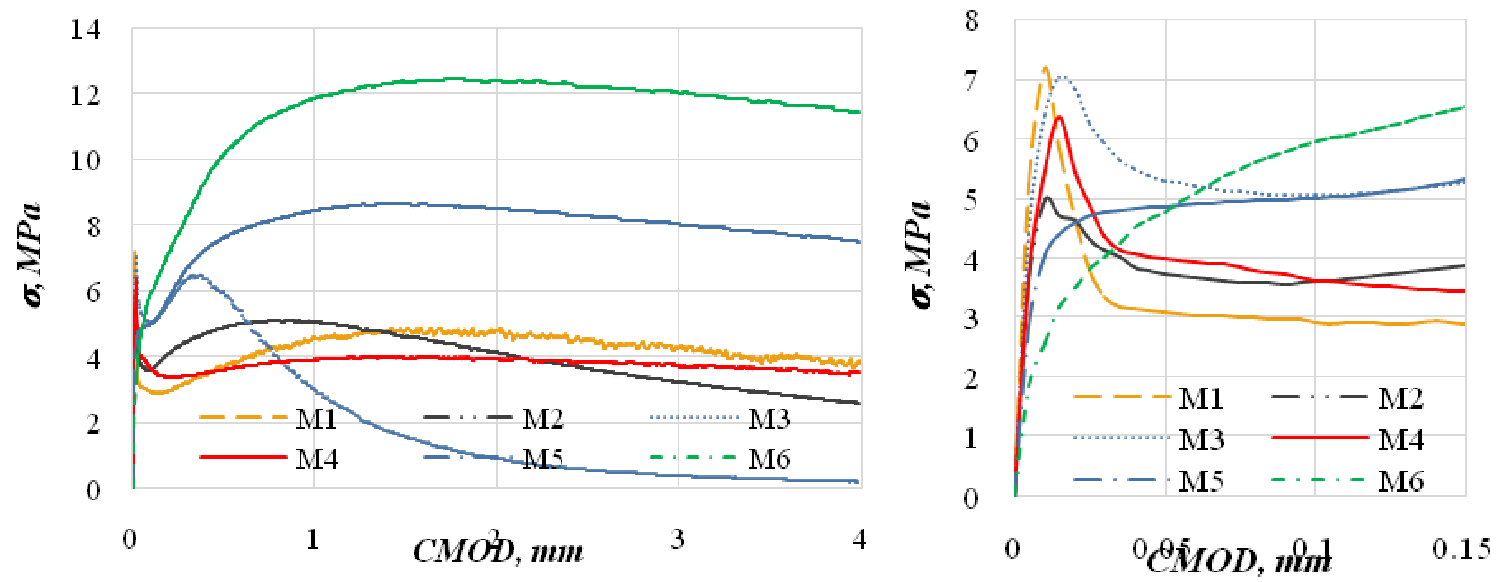

Fig. 4. Single crack bending behaviour of specimens with PP, nylon and PVA fibres with dosage: $\mathrm{M} 1, \mathrm{M} 2, \mathrm{M} 3, \mathrm{M} 4-1.0 \%$, M5 - $1.5 \%$ and M6 - $2.0 \%$ vol. fraction 
Cementitious composite mechanical properties in bending

\begin{tabular}{|c|c|c|c|c|c|}
\hline Mix & $\begin{array}{c}\text { Bending } \\
\text { strength, } \\
\text { MPa }\end{array}$ & \multicolumn{2}{|c|}{$\begin{array}{c}\text { Post-cracking } \\
\text { minimum strength, } \\
\text { MPa }\end{array}$} & \multicolumn{2}{c|}{$\begin{array}{c}\text { Post-cracking } \\
\text { maximum strength, } \\
\text { MPa }\end{array}$} \\
\hline M1 & 7.19 & 2.89 & $-60 \%$ & 4.88 & $-32 \%$ \\
\hline M2 & 5.12 & 3.57 & $-30 \%$ & 5.12 & $0 \%$ \\
\hline M3 & 7.04 & 5.06 & $-28 \%$ & 6.51 & $-8 \%$ \\
\hline M4 & 6.37 & 3.4 & $-47 \%$ & 4.01 & $-37 \%$ \\
\hline M5 & 4.86 & 4.84 & $0 \%$ & 8.68 & $79 \%$ \\
\hline M6 & - & - & - & 12.47 & - \\
\hline
\end{tabular}
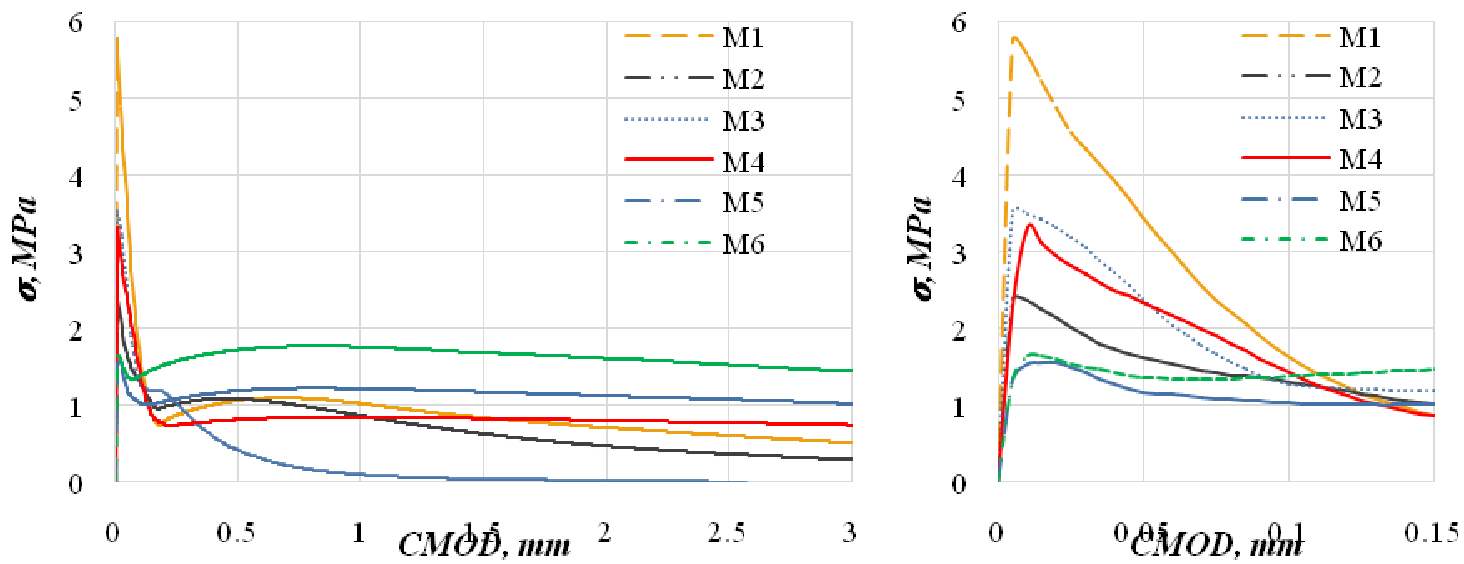

Fig. 5. Single crack tensile behaviour of specimens with PP, nylon and PVA fibres with dosage: $\mathrm{M} 1, \mathrm{M} 2, \mathrm{M} 3, \mathrm{M} 4-1.0 \%$, M5 - $1.5 \%$ and M6 - $2.0 \%$ vol. fraction

The cementitious composite M1 with nylon fibres shows the highest tensile peak strength and simultaneously a major residual strength loss after the crack development. The two composites (M3 and M4) with the second highest tensile strength are with PP and PVA fibres at $1 \%$ vol. fraction. M3 loses all strength rapidly after $0.25 \mathrm{~mm}$ of CMOD due to the small fibre length $(9 \mathrm{~mm})$. On the contrary, M4 has the longest fibres $(24 \mathrm{~mm})$ and it shows steady residual strength throughout the tensile test.Cementitious composites (M4-M6) with PP fibres at 1.0, 1.5 and $2.0 \%$ vol. fraction show clear fibre volume influence on post-cracking behaviour. With the higher fibre dosage the postcracking curve rises higher for at least $30 \%$. Tensile behaviour curves after the first crack appearance are growing faster, when the fibre dosage is higher and composite with $2.0 \%$ vol. fraction postcracking maximum exceeds the tensile strength.

Table 5

Cementitious composite mechanical properties in tension

\begin{tabular}{|l|c|c|c|c|c|}
\hline Mix & $\begin{array}{c}\text { Tensile } \\
\text { strength, } \\
\text { MPa }\end{array}$ & \multicolumn{2}{|c|}{$\begin{array}{c}\text { Post-cracking } \\
\text { minimum strength, } \\
\text { MPa }\end{array}$} & \multicolumn{2}{c|}{$\begin{array}{c}\text { Post-cracking } \\
\text { maximum strength, } \\
\text { MPa }\end{array}$} \\
\hline M1 & 5.77 & 0.74 & $-87 \%$ & 1.1 & $-81 \%$ \\
\hline M2 & 2.39 & 0.96 & $-60 \%$ & 1.09 & $-54 \%$ \\
\hline M3 & 3.55 & 1.18 & $-67 \%$ & 1.17 & $-67 \%$ \\
\hline M4 & 3.32 & 0.73 & $-78 \%$ & 0.85 & $-74 \%$ \\
\hline M5 & 1.56 & 1.01 & $-35 \%$ & 1.23 & $-21 \%$ \\
\hline M6 & 1.65 & 1.34 & $-19 \%$ & 1.77 & $7 \%$ \\
\hline
\end{tabular}

\section{Conclusions}

Fibre geometry has a pronounced influence on the fresh state rheological properties and stability of the cementitious composites. However, the fresh state rheological characteristics are affected also 
by the surface properties of the fibres. When the cementitious composite mix is designed with relatively large maximum aggregate $(4 \mathrm{~mm})$ size, it is crucial to adjust the paste volume and its viscosity to achieve a stable mix with high fibre dosage rates.

The used fibres at $1.0 \%$ vol. fraction do not allow for obtaining a strain hardening behaviour, though PP fibres with $1.5 \%$ fraction show strainhardening behaviour in bending and the same fibres with $2.0 \%$ vol. fraction show strain hardening behaviour in both - tension and bending.

A practical cementitious composite material that shows strain hardening behaviour in both tension and bending has been developed for thin overlay applications. The utilisation of relatively large maximum aggregate size of $4 \mathrm{~mm}$ provides benefits of competitiveness with traditional overlay solutions for buildings and infrastructure, and will facilitate the introduction of this material for practical applications.

\section{Acknowledgements}

In accordance with the contract No. 1.2.1.1/16/A/005 between "Competence center of smart materials and technologies" Ltd. and the Central Finance and Contracting Agency, concluded on 26th of September, 2016, the study is conducted by "Primekss" Ltd. with support from the European Regional Development Fund (ERDF) within the framework of the project "Competence center of smart materials and technologies".

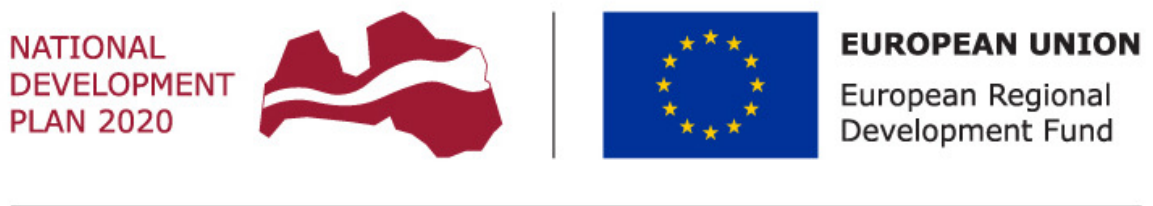

I N V E S T I N G I N Y O UR FUTURE

\section{References}

[1] Li V.C., Yang E.H., Li M. Field Demonstration of Durable Link Slabs for Jointless Bridge Decks Based on Strain-Hardening Cementitious Composites. 2008; 2003, pp. 2-111.

[2] Ma H., Qian S., Zhang Z., Lin Z., Li V.C. Tailoring Engineered Cementitious Composites with local ingredients. Constr Build Mater [Internet]. 2015;101(Part 1), pp. 584-595.

[3] Li V.C. Engineered Cementitious Composites for Structural Applications(Victor)-1998.pdf. J Mater Civ Eng. 1998;10(2), pp. 66-69.

[4] Li V.C., Lepech M., Wang S. Development of green engineered cementitious composites for sustainable infrastructure systems. Int Work Sustain Dev Concr Technol [Internet]. 2004;1(September), pp. 181-191.

[5] AASHTO T 351 Standard Method of Test for Visual Stability Index (VSI) of SeIf-Consolidating Concrete (SCC)

[6] Pereira E.B., Fischer G., Barros J.A.O. Direct assessment of tensile stress-crack opening behavior of Strain Hardening Cementitious Composites (SHCC). Cement and Concrete Research, 42, 2012, pp. 834-846.

[7] Lukasenoks A., Cepuritis R., Krasnikovs A. "Effect of the Fibre Type on the Rheological and Mechanical Properties of Cementitious Composites for Thin Overlays", Key Engineering Materials, Vol. 762, 2018, pp. 362-367. 